\title{
EL ARTE CIENTÍFICO DE LA HIGIENE ESCOLAR EN MÉXICO (1882-1950)
}

\author{
María Guadalupe García Alcaraz \\ Universidad de Guadalajara \\ mggarcia.alcaraz@gmail.com \\ Luciano Oropeza Sandoval \\ Universidad de Guadalajara \\ loropezasandoval@yahoo.com.mx
}

\begin{abstract}
RESUMEN
En este escrito examinamos la relación entre el discurso médico y la higiene escolar en el marco de la institucionalización de la educación primaria en México. El estudio va de 1882, año en que tiene lugar el Congreso Higiénico Pedagógico, hasta mediados del siglo XX, cuando se crea el Instituto Federal de Capacitación del Magisterio, organismo que incidió fuertemente en la profesionalización de los profesores en México. Analizamos los referentes teóricos que fundamentan los programas de higiene, como la eugenesia, el desarrollo que tuvo la higiene en las escuelas a partir de la creación de la Secretaría de Educación Pública (SEP) en 1921 y las concepciones que autoridades educativas y médicos tenían sobre la insalubridad y el origen de las enfermedades.
\end{abstract}

Palabras claves: Higiene escolar. Eugenesia. Salubridad.

\section{THE ART OF SCIENTIFIC EDUCATIONAL HYGIENE IN MEXICO (1870-1950)}

\begin{abstract}
In this paper, we examine the relationship between the medical discourse and school hygiene, as part of the institutionalization of elementary school in Mexico. The study goes from 1882, in which occurs the Pedagogical Hygienic Congress, until mid-twentieth century, when the Federal Institute for Teacher Training, which influenced strongly in the professionalization of teachers in Mexico is created. We analyze the theoretical framework underlying health programs, like eugenics principles, development held hygiene in schools from the creation of the Ministry of Public Education (SEP) in 1921 and conceptions that education authorities and doctors had about the unhealthiness and origin of diseases.
\end{abstract}

Keywords: School hygiene. Eugenics. Health.

\section{A ARTE CIENTÍFICA DA HIGIENE ESCOLAR NO MÉXICO (1882-1950)}

\section{RESUMO}

Neste artigo examinamos a relação entre o discurso médico e a higiene escolar no quadro da institucionalização do ensino primário no México. O estudo vai de 1882, ano em que ocorre o Congresso Higiênico Pedagógico, até meados do século XX, quando foi criado o Instituto Federal de Formação de Professores, uma organização que influenciou fortemente na profissionalização dos professores no México. Analisamos os quadros teóricos que fundamentam os programas de higiene, como a eugenia, o desenvolvimento que teve a higiene nas escolas a partir da criação da Secretaria de Educação Pública (SEP) em 1921 e das 
concepções que as autoridades educativas e os médicos tinham sobre a insalubridade e a origem de doenças.

Palavras-chave: Higiene escolar. Eugenia. Saúde.

L'ART SCIENTIFIQUE DE LA SANTÉ SCOLAIRE AU MEXIQUE (1882-1950)

\section{RÉSUMÉ}

Dans cet article, nous examinons la relation entre le discours médical et de l'hygiène scolaire dans le cadre de l'institutionnalisation de l'enseignement primaire au Mexique. L'étude va de 1882 , année où il se produit le Congrès pédagogique hygiénique jusqu'au milieu du XXe siècle, lorsque l'Institut fédéral de la formation des enseignants, une organisation qui a fortement influencé la professionnalisation des enseignants au Mexique a été créé. Nous analysons les cadres théoriques qui soutiennent les programmes d'hygiène, tels que l'eugénisme, le développement qui a eu l'hygiène dans les écoles de la création du Secrétariat de l'éducation publique (SEP) en 1921 et les conceptions que les autorités éducatives et les médecins avaient sur insalubrité et l'origine des maladies.

Mots-clés: Hygiène scolaire. Eugénisme. Santé et enseignants ruraux.

\section{INTRODUCCIÓN}

El propósito de este escrito es comprender la relación entre el discurso médico y la higiene escolar en el marco de la institucionalización de la educación primaria en México. El arco temporal que abordamos va de las últimas décadas del siglo XIX a mediados del siglo XX. Las preguntas que orientan este trabajo son: ¿Cómo es que la higiene escolar se convirtió en un tema y en un campo de acción para el Estado mexicano? ¿Cuál fue el papel de los médicos? ¿A través de qué medios y de qué mediaciones llegó el discurso de la higiene a las escuelas? ¿Cuáles fueron los principales problemas enunciados? ¿Qué medidas se dictaron para atenderlos?

Apoyándonos en Popkewitz (2002), consideramos a la higiene escolar como un sistema de razón que sustenta modos de nombrar y de actuar. Es a partir de esos sistemas que se diseñan políticas, se definen problemas y se dictan enunciados y medidas. En ese sentido, el desarrollo de las ciencias médicas a lo largo del siglo XIX estuvo articulado a la idea de producir conocimientos útiles que contribuyeran al progreso de una nación. Los médicos, poseedores de un sistema de razón, participaron en la definición de problemas de salud pública, en la formulación de medidas y en la vigilancia de cuerpos y espacios, En particular, entre los siglos XIX y XX, se construyeron narrativas de salvación en torno al niño y la familia, que en su conjunto buscaban disciplinar a la infancia en tanto deseo presente del 
futuro. Este proceso implicó la convergencia de nuevas ideas de nación, de infancia y de la familia, donde la escuela emergió como el vehículo principal para modificar prácticas, reconfigurar almas y garantizar el cambio y el progreso (POPKEWITZ, 2002).

Aquí postulamos que la estructuración de este sistema de razón, entendido como la penetración del discurso médico al espacio escolar y como la modificación individual, familiar y comunitaria, de pensamientos y prácticas asociadas a la higiene, pasa por tres etapas, las cuales sirven para ordenar la exposición de este documento:

-Los orígenes de la higiene escolar

-La higiene escolar: entre conocimiento científico y política cultural

-La higiene escolar: los maestros como operadores del conocimiento médico

\section{LA HIGIENE Y LA ORGANIZACIÓN ESCOLAR}

Desde las últimas décadas del siglo XIX, la medicina empezará a penetrar en los espacios escolares. Al calor de los avances científicos, en especial de la bacteriología, los médicos señalan que las condiciones físicas de los espacios escolares podían ser lugares de propagación de elementos patógenos. Su interés por la salud de los alumnos aparece en los años setenta de esa centuria, cuando se crea la figura del médico escolar. En ese entonces, su labor consistía en visitar tres o cuatro veces por año las escuelas, aplicar la vacuna contra la viruela, separar y "recluir" en su casa a los niños afectados por enfermedades contagiosas o por infecciones cutáneas o intestinales, elaborar estadísticas sobre la salud de los niños, realizar reportes sobre el estado higiénico de las escuelas y recomendar a las autoridades las reparaciones más urgentes (URIBE, 1911).

La intervención médica se formalizará hasta el Congreso Higiénico Pedagógico que tiene lugar en la capital del país en 1882. En este foro, médicos y profesores, aprovechando los avances de la pedagogía y de la higiene, abordarán asuntos relacionados con las condiciones higiénicas que debían tener los edificios destinados para la enseñanza elemental, con los modelos más adecuados de mobiliario escolar, con los métodos de enseñanza que podían brindar mejor instrucción a los infantes, con la distribución diaria de los trabajos escolares, con los ejercicios que debían practicar los alumnos para favorecer su desarrollo corporal, con la asunción de precauciones para evitar la transmisión de enfermedades y sobre los requerimientos que debía satisfacer una cartilla de higiene escolar (CARRILLO, 1999, p. 71-74). 
Asistentes al Congreso de Higiene en la Escuela de Minería (1882).

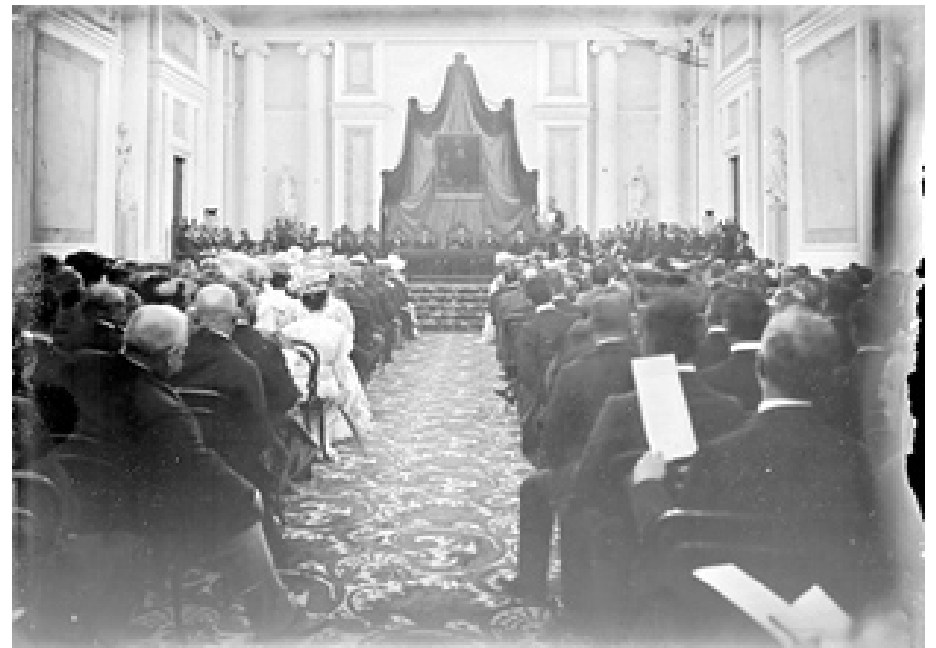

Fototeca Digital del Instituto Nacional de Antropología e Historia (INAH). Número de Inventario: 34675.

En ese evento, aunque los médicos resaltaron aspectos importantes para conservar la salud de los infantes, sus observaciones no se concretaron en políticas de intervención en los espacios escolares. Sin embargo, estas sugerencias serán retomadas en diversas entidades para promover iniciativas encaminadas a cuidar la higiene y salud de los centros escolares ${ }^{1}$.

Será hasta finales del siglo XIX y principios del siguiente, cuando empezarán a materializarse varias de las propuestas sugeridas en ese Congreso. El 3 de julio de 1896, al calor de la creación de la Dirección General de Instrucción Primaria, se establecerá una Inspección Médica e Higiénica de las Escuelas. A partir de este hecho, se crea la figura del inspector médico en las escuelas primarías del Distrito Federal. Estos facultativos tenían como obligación "cuidar, en las escuelas, la salud de los niños, las condiciones higiénicas del edificio, mueblajes y útiles; e informar a la Dirección General mensualmente, y en caso de urgencia en el acto, acerca de los resultados de las visitas que hicieren a las escuelas" (CARRILLO, 1999, p. 73).

A la vuelta de siglo, en el año de 1903, aparecerá la primera cartilla de higiene para los alumnos de las escuelas primarias, documento que será elaborado por el médico Luis E. Ruiz (1903), bajo el patrocinio de la Academia Nacional de Medicina. En este volumen se plasmarán no sólo los avances científicos en torno al origen de las enfermedades, sino también algunos saberes pedagógicos prevalecientes en torno al desarrollo que experimentan los niños y la relación que éste tiene con sus capacidades de aprendizaje. En la introducción se

\footnotetext{
${ }^{1}$ Viñao (2010) señala que, inicialmente, la relación entre la higiene y la educación se restringe al cuidado de la salud de los infantes, pero después pasará a convertirse en un asunto vinculado con el progreso social, es decir, en un deber ser, en un comportamiento indispensable para el mejoramiento de la vida social.
} 
precisa que su forma y contenido se diseñó conforme a los saberes aprendidos por los alumnos que habían cursado el cuarto año de instrucción elemental. Acorde con estas bases, en este escrito se utilizó un lenguaje sencillo, ilustraciones y nociones elementales sobre el origen de las enfermedades.

Primer libro de Higiene Escolar para los alumnos de escuelas primarias.

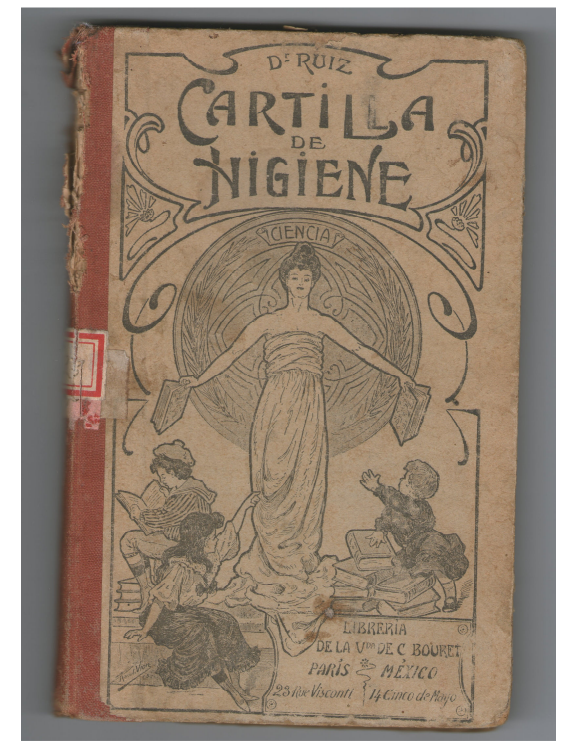

Ruiz (1903). Cartilla de Higiene Escolar.

Biblioteca Personal de María Guadalupe García Alcaraz.

Esta cartilla proporcionará a los alumnos no sólo una visión científica sobre el origen de las enfermedades -se les enseñaba que éstas eran causadas por seres vivos, infinitamente pequeños llamados microbios-, sino también las medidas higiénicas que deberán implementar para conservar la salud y evitar el contagio y propagación de esos males. Se trataba, por tanto, de un documento que buscaba introducir niveles básicos de medicalización en la conciencia de los infantes a través de la mediación de los profesores.

Al poco tiempo, en el año de 1908, el gobierno federal implementará iniciativas, donde participarán médicos higienistas y arquitectos, orientadas a intervenir en las condiciones materiales de los edificios escolares y en la revisión del estado físico de los alumnos. A través de programas de revisión de los espacios escolares ${ }^{2}$ y mediante la

\footnotetext{
2 "El meollo del discurso higiénico consistió en la regulación del espacio escolar y por consiguiente, en normar las condiciones materiales de los edificios, el mobiliario de clase y el material de enseñanza. El espacio escolar salubre se equiparó a un ambiente moral deseable, de ahí que fuera preciso remediar la habilitación de los edificios y los problemas sanitarios de una red escolar compuesta en su mayoría por casas particulares rentadas que habían sido adaptadas para escuela y que acentuaban una problemática sanitaria muy seria" (CHAOUL; 2012, p. 257).
} 
aplicación de estudios individuales a los alumnos ${ }^{3}$, se concretará la articulación del discurso médico con políticas educativas encaminadas a higienizar los espacios escolares y a los sujetos asistentes a los mismos.

Estas iniciativas no serán una intervención ocasional, sino una política de gobierno que prevalecerá a pesar del cambio de régimen hasta la caída de Victoriano Huerta en 1914. Esta intervención no resolverá los problemas de infraestructura ni la falta de higiene en los edificios escolares, pero sentará un precedente que será retomado por los gobiernos posteriores a la Revolución Mexicana, a través de instituciones vinculadas a la higiene escolar, como la Secretaria de Educación Pública y el Departamento de Salubridad Pública.

\section{LA HIGIENE ESCOLAR, ENTRE CONOCIMIENTO CIENTÍFICO Y POLÍTICA CULTURAL}

Una vez concluida la parte más cruenta del movimiento armado, los programas higienistas pasarán por una etapa donde la emergencia de nuevos referentes en torno a la evolución de la infancia y la salubridad pública, incidirán en su estructura y aplicación. A la par de los avances médicos, con la creación de la Secretaría de Educación Pública (SEP) en 1921, se impulsarán programas educativos donde se desarrollarán actividades de promoción de la higiene entre los alumnos y las comunidades aledañas a las escuelas. Así, desde disciplinas ligadas a la medicina y desde el campo de la enseñanza, a lo largo de los años veinte y treinta del siglo $\mathrm{XX}$, se generarán nuevos saberes y experiencias en torno a la higiene escolar.

\section{La Infancia desde las Instituciones de Salud}

Desde los años veinte del siglo anterior, tienen lugar sucesos que ayudan a demarcar los ejes desde donde los médicos abordarán los asuntos de la infancia y la higiene escolar. En 1921 se lleva a cabo el Primer Congreso del Niño Mexicano, evento en el que sobresale la presencia de un discurso eugenista que incidirá en la fundamentación de programas para el desarrollo saludable de la infancia. Apoyados en disciplinas emergentes como la psicología, la genética y la bacteriología, los eugenistas mexicanos se enfocarán en tres elementos claves de

\footnotetext{
3 Una vez remodelado el espacio escolar, con cambios acordes a las prescripciones higiénicas, los médicos inspectores procedieron a intervenir en los cuerpos de los alumnos. Así, se empezó a revisar "las condiciones de aseo en que llegaban los alumnos, para evitar la propagación de los parásitos de la cabeza y del cuerpo (CHAOUL, 2012, p. 277).
} 
la reproducción y la socialización: en la maternidad, la sexualidad y los niños. Estos especialistas se preocuparán por el ciclo entero de la maduración de los infantes, desde los momentos previos de la concepción hasta la pubertad y la iniciación a la adultez. En este cuidadoso escrutinio, las aulas de las escuelas se convertirán en laboratorio para la medición, clasificación y rastreo de los niños, donde la antropometría y la psicometría llegarán a ser las prácticas privilegiadas para discernir entre lo normal y lo anormal.

Al calor de los presupuestos de la eugenesia se creará, en 1921, el Servicio de Higiene Escolar del Departamento de Salubridad Pública. Esta dependencia será el espacio donde se plasmarán las recomendaciones del Congreso del Niño Mexicano. Así, en consonancia con este antecedente, se establecerá en 1922 el primer Centro de Higiene Infantil, agencia que promoverá iniciativas orientadas a supervisar la evolución prenatal, a través de las mujeres embarazadas, el nacimiento y la crianza de los niños. Este tipo de atención crecerá en la ciudad de México en los años veinte hasta llegar a 10 establecimientos.

Por medio del servicio de higiene infantil, permeado fuertemente por el discurso eugenista, el Estado empezará a penetrar en el espacio familiar: a través de las enfermeras visitantes extenderá su alcance hasta el interior del espacio doméstico, lugar donde éstas transmitirán a las madres y a los demás integrantes de las familias los preceptos básicos de la higiene. Así, bajo el lema de crear "La Gran Familia Mexicana", los eugenistas y los higienistas infantiles procederán a reorientar la conducta de las madres. Ellos introducirán la noción de la maternidad consciente, concepto que buscará involucrar a las mujeres en el ejercicio de prácticas de crianza más estrictas y cuidadosas, que ayuden "a generar una descendencia más vigorosa y sana" (STERN, 2002, 303).

Otro evento de gran trascendencia para el desarrollo de la higiene escolar, se relaciona con la fundación de la Escuela de Salubridad, suceso que tendrá lugar en marzo de 1922. Con la creación de esta institución se sentarán las bases para la formación de profesionistas vinculados con la salubridad y se abrirá un espacio para la experimentación de proyectos en torno a esa problemática. En esta encomienda, la comunidad de esa Escuela adoptará algunos paradigmas utilizados en el plano internacional, como sucede con las propuestas sanitaristas vigentes en los Estados Unidos ${ }^{4}$. Sin embargo, a principios de los años treinta sus miembros se abrirán a las ideas propuestas por la medicina social, concepción que les permitirá superar "el reduccionismo que había generado el énfasis exagerado en la bacteriología y el descubrimiento de los micro-organismos como causa de muchas

\footnotetext{
4 Ordoñez (1989) señala que, a partir de 1921, la Fundación Rockefeller participó activamente en la formación de sanitaristas y en acciones de medicina preventiva y salud pública en México.
} 
enfermedades infecciosas", y acceder a visiones que les ayudarán a pensar que la salud y la enfermedad no solo dependían de factores biológicos, sino también de condiciones sociales, políticas y culturales (GUDIÑO, MAGAÑA y HERNÁNDEZ, 2013). Así, la medicina social vendrá a proponer a los médicos una visión holística de la salud pública que fincará el origen de muchas dolencias en la pobreza, la falta de educación, la indiferencia política y el prejuicio.

Al amparo de este concepto, El Departamento de Salubridad Pública promoverá varias iniciativas importantes en materia de salud, donde destacará la movilización de médicos y salubristas hacia el campo, tratando de sensibilizarlos con la realidad social que vivía la gente ${ }^{5}$. Para los segundos se planearán prácticas de campo afuera de la escuela, en estaciones de adiestramiento promovidas por la Fundación Rockefeller. Con estas acciones se erigirá el enlace entre los egresados de la Escuela de Salubridad y las comunidades, pero sobre todo se fomentará en ellos mayor conciencia del entorno social y cultural de las colectividades con las que debían trabajar.

Niños durante la semana de Higiene Infantil.

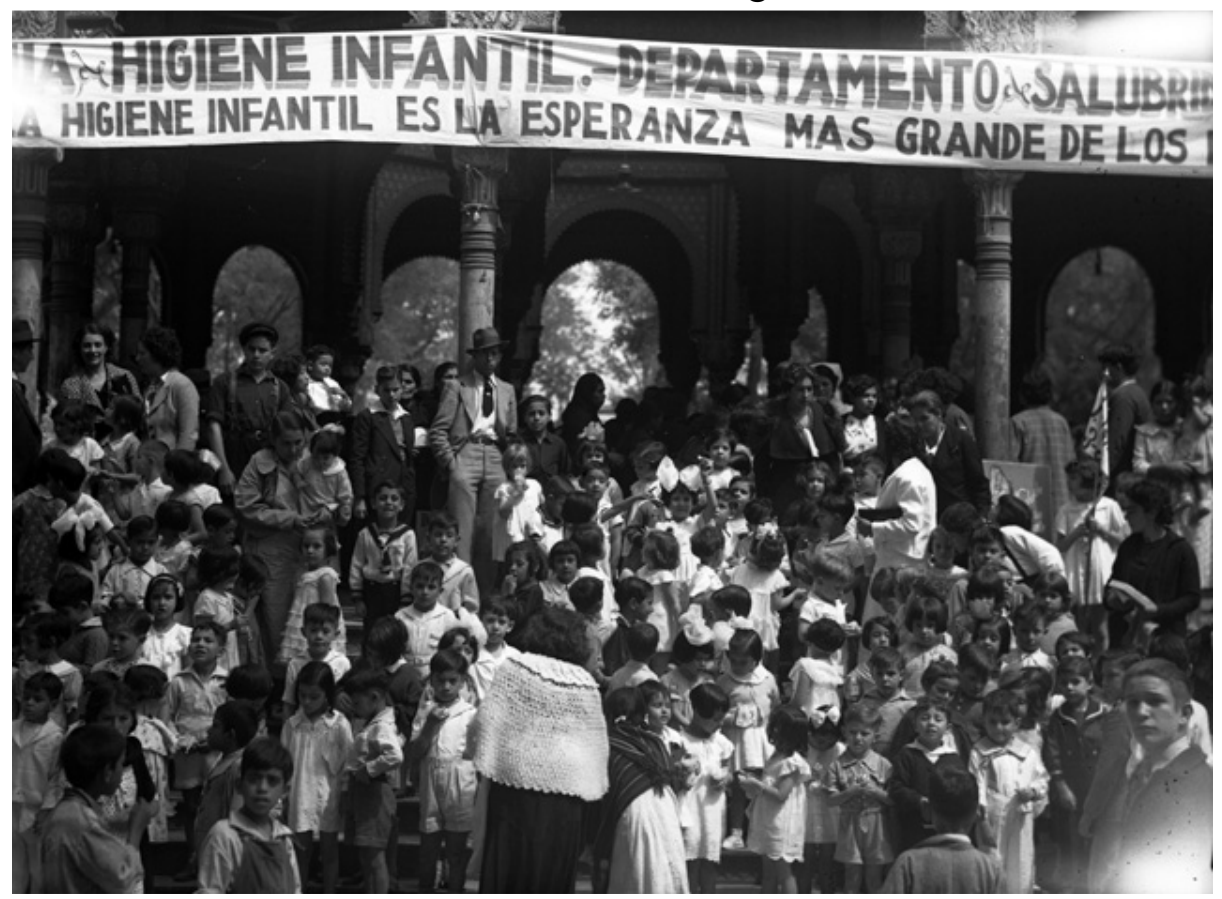

Fototeca Digital del Instituto Nacional de Antropología e Historia (INAH). Número de Inventario: 141359.

\footnotetext{
${ }^{5}$ Gudiño, Magaña y Hernández (2013, p. 86) dicen que los intentos más importantes en materia de salud en los años treinta, al calor del influjo de la medicina social, fueron tres: "primero el plan de Coordinación y Cooperación de los servicios sanitarios federales y locales de la República, propuesto por el doctor Miguel Bustamante desde 1934. Segundo, la puesta en marcha del Código Sanitario de 1934 y por último, la movilización de médicos al interior del país mediante el servicio social."
} 
Para finales de los años treinta y principios de los cuarenta, el influjo de la medicina social y la experiencia desarrollada por las brigadas sanitarias, permitirá a los médicos y funcionarios vinculados con la salubridad pública generar propuestas que irán más allá de los programas implementados por los propios brigadistas. Los salubristas empezarán a visualizar que el origen y evolución de los problemas de salud no se reducía al individuo enfermo, sino que involucraba las condiciones materiales de vida de la población, donde las prácticas y creencias vinculadas con el cuidado personal y la convivencia colectiva, tenían estrecha relación con el nacimiento y desarrollo de las enfermedades. En esas circunstancias, se considerará que la incorporación de contenidos curriculares relacionados con la higiene y prevención de enfermedades a la educación primaria, podría ayudar a sustituir las creencias y costumbres por saberes fundamentados en la medicina y la salubridad pública.

\section{La Higiene como Política Cultural}

En paralelo con los avances de la medicina y la salubridad pública, se impulsará un ambicioso proyecto social que buscará llevar la educación primaría a todos los rincones del país. A través de la creación de la Secretaría de Educación Pública (SEP) en 1921, se emprenderá un programa de expansión que se ubicará preferentemente en las zonas rurales. Con esta propuesta no sólo se intentará alfabetizar a mayor número de campesinos, sino también promover cambios en su forma de vida: se pretendía crear "un nuevo hombre, sano, diligente y moral, y homogeneizar hábitos y costumbres en bien de la unidad nacional" (LOYO, 2010, p. 163). 
Zinacantecos reunidos junto a una escuela rural (1930).

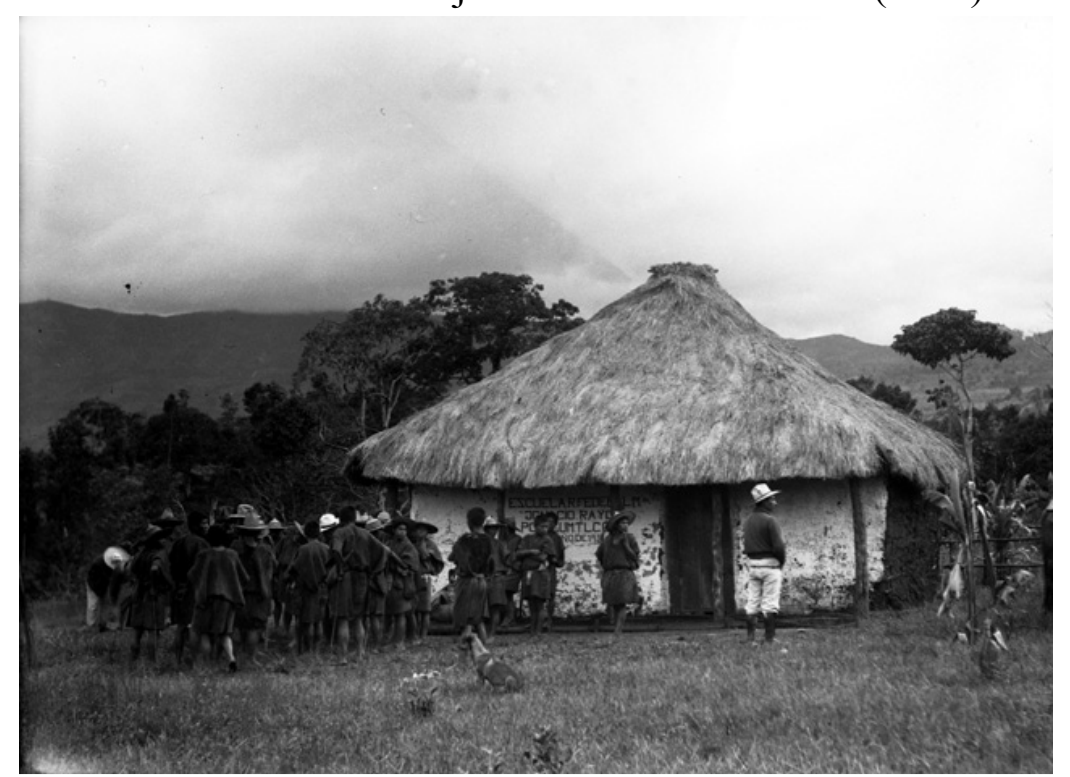

Fototeca Digital del Instituto Nacional de Antropología e Historia (INAH). Número de Inventario: 188528.

Para llevar a cabo este proyecto, se crearon las misiones culturales. Estas unidades fueron creadas en 1923 y se integraron por individuos con diferentes conocimientos y habilidades, como economía doméstica, agricultura, industrias, música, arte, educación física y enseñanzas académicas. Esas agrupaciones “apoyaron la preparación de los primeros maestros rurales federales y llevaron a las comunidades un mensaje 'civilizador'. Por medio de cursos o "institutos" que duraban inicialmente 21 días y después cuatro semanas, los misioneros intentaban capacitar a los docentes y, además, mejorar el trabajo, la producción y la vida cotidiana de los vecinos" (LOYO, 2010, p. 164).

Estos objetivos civilizadores se enfatizarán con el arribo de Plutarco Elías Calles a la presidencia de México en diciembre de 1924. Este nuevo mandatario no solo seguirá apoyando la extensión de la educación rural, sino "también buscará homogeneizar sus hábitos y manifestaciones culturales y hacer al trabajador más productivo y eficiente, así como modernizar y moralizar a la población por medio de una religión cívica y campañas contra el fanatismo y en pro de una vida sana e higiénica" (LOYO, 2010, p. 165). Así, en las escuelas rurales se desarrollará una gama de acciones encaminadas a "transformar los hábitos domésticos, modernizar las técnicas agrícolas y las industrias rurales, combatir supersticiones, prácticas arcaicas y vicios, promover campañas de higiene y salud, fomentar la recreación, las manifestaciones artísticas y los deportes" (LOYO, 2010, p. 166-167).

En este vasto programa de labores se insertará la enseñanza de la higiene escolar, actividad que se desplegará en consonancia con las visiones predominantes en torno al atraso 
prevaleciente en el medio rural. En ese entonces, se consideraba que muchos de los problemas sociales que afectaban a los pobladores del campo, se debían a la ignorancia de la gente. Esa apreciación llevará a inspectores y maestros, a utilizar los saberes sobre la higiene como un referente para alentar cambios culturales en sus educandos y en la comunidad. Así, para erradicar las enfermedades asociadas con la insalubridad y la falta de higiene, se estimará pertinente enseñarles a alimentarse adecuadamente, a evitar el alcoholismo, a vestirse y asearse de forma apropiada, y a mantener un ambiente higiénico en la casa y en los lugares de uso colectivo.

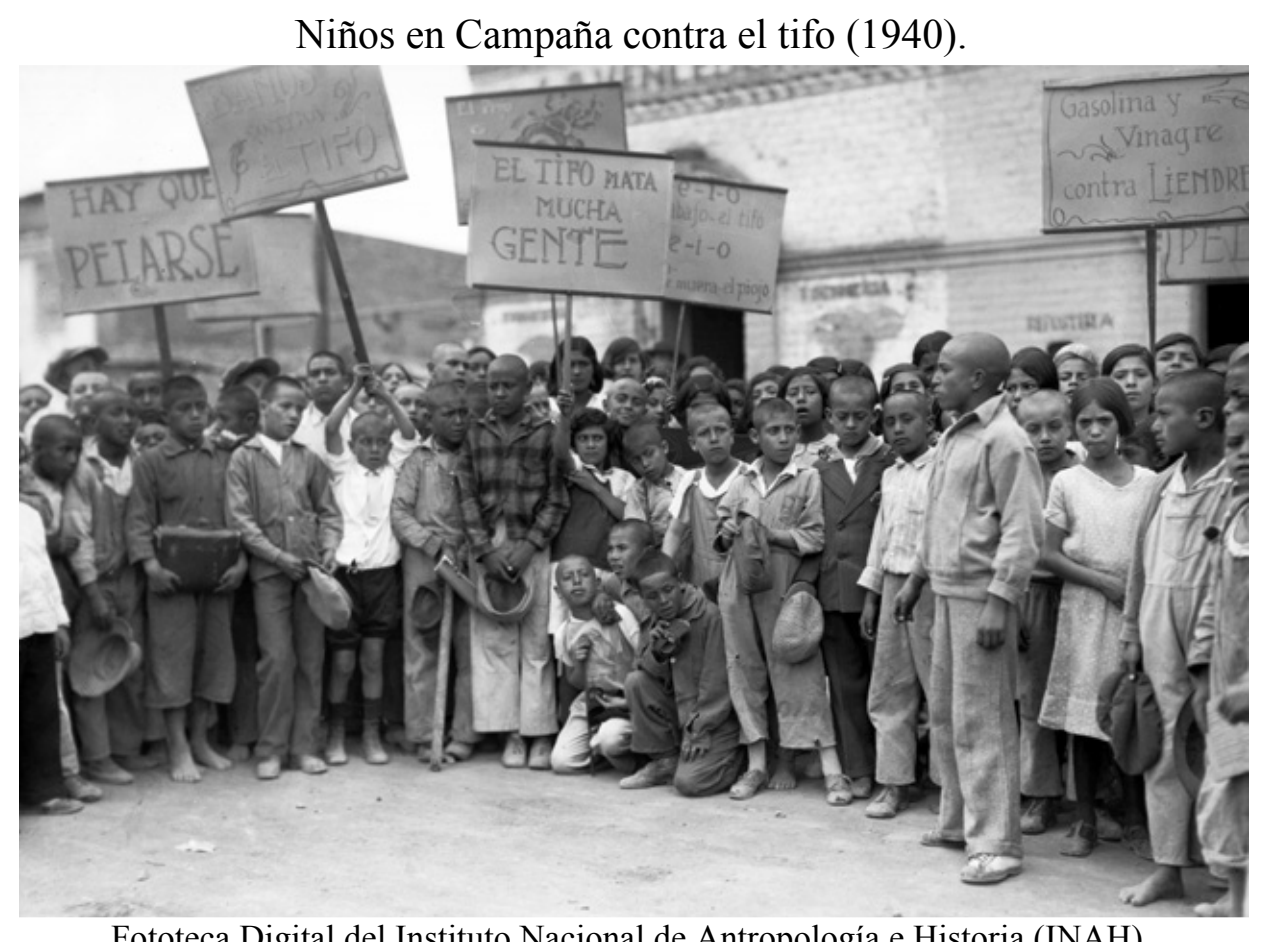

Fototeca Digital del Instituto Nacional de Antropología e Historia (INAH). Número de Inventario: 5870.

Con estas actividades, autoridades educativas y profesores irán creando su propia experiencia en torno a la higiene. La SEP, por ejemplo, apelará a una de las tradiciones formativas implementadas por los propios docentes: a través de conferencias "pedagógicashigiénicas" difundirá los conocimientos básicos de esa disciplina entre los profesores. Esa vía de transmisión, por lo demás, no evolucionará separada de las iniciativas impulsadas por los médicos y salubristas, ya que los encargados de impartir esas conferencias serán los propios médicos. Los profesores, por su parte, desarrollarán una forma de apropiación de esos saberes que incidirá en las expresiones concretas que tomará la promoción de la higiene: ellos no centrarán su interés en la enseñanza formal de los principios científicos en que ésta se 
sustentaba, sino en su uso práctico, en la modificación de los hábitos de sus alumnos y de los miembros de la comunidad.

Esta forma de implementación de los programas sanitarios se verá fortalecida en los años treinta, década donde se incrementarán las campañas de vacunación, de salud comunitaria y las acciones contra el alcoholismo. Durante esos años el trabajo social de los profesores acusará algunas variantes relacionadas con las iniciativas políticas promovidas por los gobernantes y dirigentes políticos, como Plutarco Elias Calles y Lázaro Cárdenas. Así, su trabajo de enseñanza se entrelazará con las acciones que emprenderán uno y otro gobernante.

En los primeros años de ese decenio, Plutarco Elías Calles, líder máximo de los gobiernos revolucionarios, radicalizará su posición en torno a la formación ideológica de los mexicanos. En ese posicionamiento arremeterá contra la Iglesia católica, buscando reducir su papel en el campo de la enseñanza. Esre afán por desplazar al clero del ámbito educativo, desembocará en la reforma del artículo $3^{\circ}$ constitucional. En diciembre de 1934, "se sancionará el derecho del Estado a controlar la educación como medio para excluir a la Iglesia, combatir el fanatismo y los prejuicios religiosos y crear en la juventud un concepto racional del universo y de la vida social" (VAUGHAN, 1997, p. 87). A través de esta enmienda constitucional se establecerá que la educación impartida por el Estado tendrá una orientación socialista.

Esta controversia involucrará directamente a los profesores, porque ellos serán los operadores del Plan de Accion de la Escuela Socialista. Así, ya como promotores de los contenidos de enseñanza oficial, como opositores a los postulados socialistas o como participantes en las demandas obreras y campesinas, los docentes intervendrán en las distintas fases que asumirá esta propuesta educativa. En una primera etapa, que irá de 1934 a mediados de 1935, promoverán la "desfanatización” de los ciudadanos e inculcarán en los niños principios de justicia social y lucha de clases. En los años siguientes, en pleno gobierno del general Lázaro Cárdenas, el programa oficial se vinculará más estrechamente "con la movilización de los obreros y campesinos por la lucha de sus derechos constitucionales, [como] tener tierra, ingreso y condiciones de trabajo decentes y ejercer derechos como ciudadanos y como miembros de las organizaciones de masas" (VAUGHAN, 1997, p. 88).

En este plan socialista se siguió utilizando el trabajo docente como un programa de acción orientado a mejorar las condiciones materiales de la población. Sin embargo, a diferencia de la década precedente, la labor de los profesores se orientará a superar la desigualdad social: ellos preconizarán entre sus alumnos y la comunidad, el reparto de la 
propiedad agrícola, la lucha de clases y participarán en las movilizaciones de las organizaciones populares.

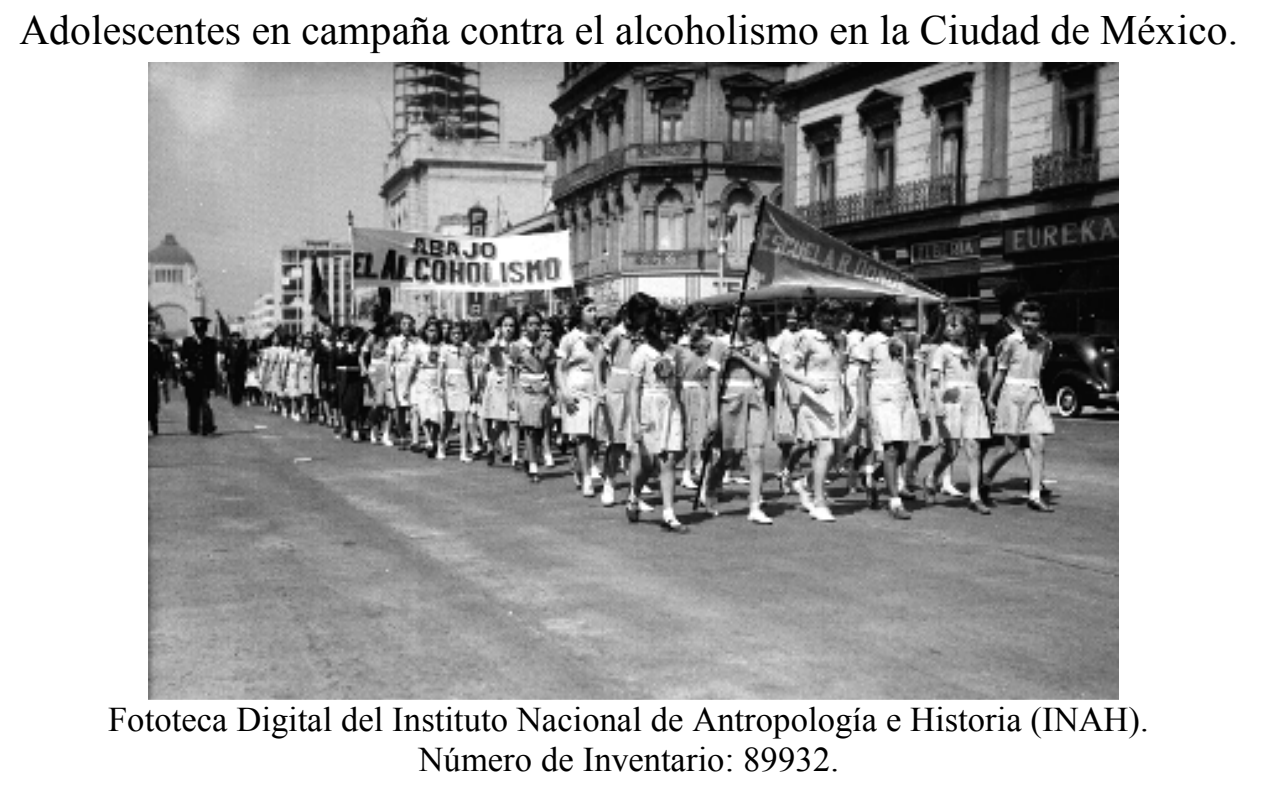

Independientemente de la congruencia del programa de la escuela socialista y de los fines políticos que tuvo durante el gobierno de Lázaro Cárdenas, los profesores pusieron en juego sus habilidades de enseñanza y colaboraron en la promoción de los contenidos de esa propuesta; en esa labor ampliaron su capacidad operativa para difundir los saberes y conocimientos vinculados con la salubridad y la higiene escolar. Así, a pesar de la vorágine social y política que se vivirá en esa década, ellos proseguirán promoviendo cambios en los hábitos de sus alumnos y los miembros de la comunidad.

Podemos decir que el campo educativo fue un laboratorio en el que se ensayaron diversos proyectos, que pasaron por la formación de un pueblo alfabetizado con lecturas clásicas (José Vasconcelos), la capacitación de comunidades trabajadoras, hasta llegar al proyecto de la escuela socialista, bajo el mandato del presidente Lázaro Cárdenas. En todos esos momentos se implementaron varias propuestas educativas donde los profesores plasmaron sus saberes prácticos y su experiencia en la renovación de las creencias y costumbres, elementos que fueron indispensables no solo para mejorar las condiciones económicas y sociales de los pobladores, sino también para promover la reconfiguración de las relaciones de poder económico y político prevalecientes en las zonas rurales ${ }^{6}$.

\footnotetext{
${ }^{6}$ Ver GUEVARA (1983).
} 


\section{LA HIGIENE ESCOLAR: LOS MAESTROS COMO OPERADORES DEL CONOCIMIENTO MÉDICO}

Al arribar los años cuarenta del siglo XX, después de la lucha armada, de la gestación de instituciones, de las disputas ideológicas y de las constantes manifestaciones populares, los grupos gobernantes dejarán atrás la confrontación y avanzarán hacia un proyecto que buscará promover el trabajo y el progreso, anhelo que requería la conformación de un pueblo sano y educado. Esta premisa precisaba fundar nuevas instituciones, o bien ampliar la cobertura de las ya existentes. En materia de salud, se creará la Secretaría de Salubridad y Asistencia en 1943, organismo que sustituirá al Departamento de Salubridad Pública, y la SEP, por su parte, extenderá su infraestructura e impulsará un amplio proyecto de capacitación para los maestros no titulados ${ }^{7}$.

En la capacitación de los maestros convergerán los intereses de la Secretaría de Salubridad y Asistencia, en particular las inquietudes de los salubristas por extender el conocimiento de la higiene a la mayoría de la población, y de la Secretaría de Educación Pública, de contar con apoyo especializado en la elaboración de los materiales que servirán para fundamentar la formación de los profesores no titulados. Así, dentro de una diferenciación de funciones acorde a la especialización técnica y el estatus de los integrantes, se institucionalizará la introducción del discurso médico a la escuela: los médicos elaborarán libros de texto sobre la higiene escolar y los profesores se tornarán en los responsables de la difusión de esos conocimientos y saberes dentro del aula y de la comunidad.

Ese acercamiento entre el discurso médico y la formación de los docentes se concretará en uno de los proyectos más importantes en torno a la capacitación magisterial: en el Instituto Federal de Capacitación del Magisterio (IFCM).

\section{La Creación del IFCM}

El IFCM se creó a finales de 1944 con el objeto de responder a las necesidades de formación de los maestros en servicio no titulados, la mayoría de ellos ubicados en escuelas

\footnotetext{
${ }^{7}$ Al llegar a la dirección de la SEP, en 1943, Torres Bodet orientó la acción de ese organismo a la realización de cinco empresas fundamentales: "instaurar una campaña nacional de alfabetización, establecer un programa efectivo de construcción de escuelas, organizar la capacitación de los maestros no titulados, revisar los planes, los programas y los libros de texto vigentes, y al final del periodo, reformar el artículo 3o. constitucional." (ARNAUT, 1998, p. 221).
} 
rurales. ${ }^{8}$. Este organismo ofrecía la formación en fases: "la escuela por correspondencia" y "la escuela oral"9. Para la Escuela por Correspondencia, se elaboró material bibliográfico que sirvió de base para transmitir a los profesores conocimientos y saberes orientados a darles mayores elementos pedagógicos para el trabajo de enseñanza, para implementar programas de alfabetización y para desarrollar trabajo comunitario. Al terminar los cursos por correspondencia, el profesor se presentaba en el verano a la "escuela oral", con duración de seis semanas, para concluir con un examen final.

Los conocimientos que ofrecía el IFCM iban más allá de la formación de competencias pedagógicas, pues se visualizaba el papel del profesor como un agente promotor de cambios culturales en la comunidad, aunque ya no con el radicalismo de los años veinte y treinta. En esa perspectiva, se les formaba en saberes relacionados con la enseñanza, con contenidos disciplinares, con la organización del trabajo escolar, con la salud y bienestar de los alumnos y con la participación social en la comunidad. Este acervo era indispensable para afrontar las condiciones materiales y sociales de las comunidades, porque los profesores tenían que asumir tareas de promoción, de obtención de apoyos y gestoría, labores necesarias para hacer mínimamente funcional el espacio escolar. Por ejemplo, muchos de ellos llegaron a participar en la construcción de las mismas escuelas, en el equipamiento escolar, en la introducción de agua potable y drenaje y en el mejoramiento de las condiciones de vida de los pobladores de la comunidad ${ }^{10}$. Estas actividades, por lo demás, se desarrollaron en ambientes de tensión social, donde los profesores tenían que ganarse la aceptabilidad de las autoridades y los miembros de la comunidad.

El IFCM inicio sus propuestas de capacitación con un plan de estudios similar al de la Escuela Nacional de Maestros. Sin embargo, al arribar a los años cincuenta, la creciente demanda de sus servicios levará a este organismo a ampliar su infraestructura: en esa década

\footnotetext{
${ }^{8}$ La expansión educativa que se vive en México desde los años veinte, es atendida principalmente con profesores poco preparados para afrontar los objetivos de enseñanza. En esa década, según Aurora Loyo, 20\% no había estudiado más allá del cuarto año, $50 \%$ apenas había terminado su educación primaría y "aproximadamente $8 \%$ había visitado una escuela normal, o cursado en ella uno o dos años." (LOYO, 2010, p. 66-67) Esa situación no cambió mucho para los años cuarenta, porque en el umbral de esa década, cerca del $70 \%$ de los profesores no contaba con título (SOLANA, 1981).

${ }^{9}$ Diario Oficial, Órgano del Gobierno Constitucional de los Estados Unidos Mexicanos, Tomo CXLVII, $\mathrm{n}^{\circ} .50$, México, D.F., a 30 de diciembre de 1994, p. 15 y 16.

${ }^{10}$ Castillo señala que en 1944 se envió una circular indicando que los maestros rurales debían vivir en las comunidades donde prestaban sus servicios. El documento incluía cinco puntos: "1. Atender debidamente a los niños de edad escolar [...] y dedicar atención a los adultos analfabetos para enseñarles a leer y escribir. 2. Influir sobre los habitantes de la comunidad para modificar sus costumbres mejorando sus hábitos de vida. 3o. Despertar el sentimiento de amor a la patria e impulsar el cumplimiento de los deberes cívicos. 4o. Abstenerse de tomar parte en las luchas de carácter político de la localidad y $5^{\circ}$. A la parcela escolar convertirla en una granja que sirva de modelo a los campesinos para ir mejorando sus cultivos." (Circular no. 3885, AHSEP, Caja 5664, referencia IV/130/ (IV-5) (725.4)/1, (Cit. por CASTILLO, 2010, p. 96-97).
} 
se crearán 12 subdirecciones regionales, 38 agencias coordinadoras y 1800 centros de estudio y consulta. ${ }^{11}$ Para apoyar el trabajo de formación, El IFCM publicará más de doscientos títulos que formarán parte de la Biblioteca Pedagógica del Magisterio y distribuirá diversos materiales impresos para las etapas de educación a distancia. Así, a lo largo de esa década, 6,000 profesores, que laboraban principalmente en comunidades rurales, obtendrán su título para ejercer el magisterio; esta cohorte será "entrenada" a través de textos teóricos y prácticos escritos por médicos, para difundir la higiene en las escuelas y comunidades. Los libros relacionados con las ciencias médicas, escritos por galenos, fueron Higiene escolar (libro y cuaderno de trabajo), de Roque Ramírez Rodríguez, e Higiene dietética (en dos tomos), de José Quintín Olascoaga.

En esta forma de capacitación se concretará uno de los grandes proyectos que médicos y salubristas fueron madurando a lo largo de los años veinte y treinta del siglo XX: la incorporación de los conocimientos científicos de la higiene a la enseñanza formal. Con el correr de los años los conocimientos en torno a la higiene tomarán forma en los libros de texto-únicos, gratuitos y obligatorios- destinados a los niños que se distribuyeron en todas las escuelas del país.

\section{REFLEXIONES FINALES}

¿Cómo fue la relación entre el discurso médico y la higiene escolar en el marco de la institucionalización de la educación primaria en México? Con lo expuesto en este documento pudimos observar que la higiene escolar es un campo social construido por la imbricación entre conocimientos y prácticas. En la configuración histórica de este tejido los médicos se erigieron como poseedores de un saber constitutivo de un proceso civilizatorio que tomó forma en la creación de instituciones de salud, pero también en las de educación. A lo largo del periodo de estudio la escuela se fue consolidando como un espacio de intervención y como un laboratorio cultural para transformar a los individuos e integrarlos a un proyecto nacional.

Para fundamentar la higiene escolar, los médicos pasaron de priorizar los postulados de la bacteriología a considerar los problemas de salud como asociados a la persistencia de costumbres y creencias, por lo que se requería cambiar las mentalidades. La escuela fue ubicada como "la institución" desde la cual se podían operar programas de largo alcance para

\footnotetext{
${ }^{11}$ En 1971 desaparece el IFCM para ser sustituido por la Dirección General de Capacitación Mejoramiento Profesional del Magisterio (DGCMPM).
} 
modificar las prácticas de higiene, no sólo de los niños, sino de los miembros de la comunidad en la que se asentaba la escuela. En esta lógica, la eugenesia proveyó a los galenos de referentes para justificar las medidas higiénicas, pues sólo garantizando una vida sana y libre de vicios a la niñez mexicana se podrían "regenerar" la raza y contar con una población trabajadora.

En este sentido, los saberes y experiencias acumulados en esos años, les permitieron a los médicos visualizar que el impacto de las campañas higiénicas requería la generación de hábitos diferentes en la población, proceso que precisaba ampliar el campo de acción de los brigadistas. Ellos empezaron con la intervención en el espacio familiar, tomando a las madres como interlocutores de sus campañas de sanidad, pero después observaron que este ámbito era insuficiente para generar cambios culturales sino se complementaba con acciones estructuradas desde los espacios de instrucción formal.

Este ensamble entre el discurso médico y la educación, fue posible no sólo por los niveles de desarrollo que alcanzó la salubridad pública y el sistema educativo nacional, sino también por los cambios políticos y de orientación ideológica del Estado mexicano a partir de los años cuarenta. En esa década, la idea de la unidad nacional sustituirá a la confrontación social, giro que afectó la forma de concebir a la educación y la salud de la población. La salud de la niñez y de los trabajadores se estimará como fundamental para contar con recursos humanos capaces de participar en el desarrollo económico y social. A su vez, la educación será visualizada como un medio fundamental para transmitir los valores y creencias que permitirán establecer las bases de la identidad nacional, proceso donde la higiene escolar pasará a formar parte de los requerimientos del desarrollo social de la infancia, es entonces que se refuerza la idea de que los profesores deben ser los promotores y mediadores de la higiene escolar, para los cual había que formarlos sistemáticamente en esos saberes y prácticas.

\section{BIBLIOGRAFÍA}

ARNAUT, Alberto. Historia de una profesión. Los maestros de educación primaria en México, 1887-1994. México, SEP/CIDE, Biblioteca del Normalista, 1998.

CARRILlO, Ana María. El inicio de la higiene escolar en México: Congreso Higiénico Pedagógico de 1882. Revista Mexicana de Pediatría, México, vol. 66, núm. 2, p. 71-74, mar/abril, 1999. 
CASTILLO TAPIA, Salvador. Sembradoras del saber. Toluca, México, Secretaría de Educación del Gobierno del Estado de México/Servicios Educativos Integrados al Estado de México, 2010, 184 p.

CHAOUL, María Eugenia. La higiene escolar en la ciudad de México en los inicios del siglo XX, Historia mexicana, México, vol. LXII, núm. 1, p. 249-304, julio-septiembre de 2012.

DIARIO Oficial, Órgano del Gobierno Constitucional de los Estados Unidos Mexicanos, Tomo CXLVII, nº. 50, México, D.F., a 30 de diciembre de 1994, p. 15 y 16.

GUDIÑO, María Rosa; MAGAÑA, Laura y HERNÁNDEZ, Mauricio. La Escuela de Salud Pública: su fundación y primera época, 1922-1945. Salud Pública, México, vol. 55, núm. 1, p. 81-91, enero-febrero de 2013.

GUEVARA NIEBLA, Gilberto. El saber y el poder. México, UAS, 1983, 225 p.

VAUGHAN, Mary Kay. Cambio ideológico en la política educativa de la SEP: programas y libros de texto, 1921-1940. En: QUINTANILLA, Susana y VAUGHAN, Mary Kay (Coordinadoras). Escuela y sociedad en el periodo cardenista. México, Fondo de Cultura Económica, 1997, p. 76-108.

LOYO, Engracia. La educación del pueblo. En: TANCK, Dorothy (Coord.). La educación en México. México, El Colegio de México, 2010, p. 154-187.

ORDOÑEZ, Blanca Raquel. Epidemiología. En: SOBERÓN, Guillermo, KUMATE, Jesús y LAGUNA, José (Comp.). La salud en México: testimonios 1988. México, Fondo de Cultura Económica, Tomo IV, núm. 2, 1989, p. 227-237.

POPKEWITZ, Thomas. Infancia, modernidad y escolarización: nacionalidad, ciudadanía, cosmopolitismo y los 'otros` en la constitución del sistema educativo norteamericano. En: PEREYRA, M., GONZÁLEZ, C. y CORONEL, J. Infancia y escolarización en la modernidad tardía. Madrid, Ediciones Akal/Universidad Internacional de Andalucía, 2002, p. 17-69.

RUIZ, Luis E. Cartilla de higiene escrita para la enseñanza primaría. México, Librería de la Vda. de Bouret, 1903, 88 p.

SOLANA, Fernando; CARDIEL, Raúl y BOLAÑOS, Raúl. Historia de la Educación Pública en México. México, FCE, 1981.

STERN, Alexandra. "Madres conscientes y niños normales: la eugenesia y el nacionalismo en el México pos revolucionario". En: CHÁZARO, Laura (Coord.). Medicina, ciencia y sociedad en México, siglo XIX. Michoacán, México, El Colegio de Michoacán/Universidad Michoacana de San Nicolás de Hidalgo, 2002, p. 293-336.

URIBE, Troncoso M. Reseña de la organización del servicio higiénico escolar en el Distrito Federal y sus resultados. Gaceta Médica de México, México, T. VII, núm. 43, julio de 1911, p. 331-349.

VIÑAO FRAGO, Antonio. Higiene, salud y educación en su perspectiva histórica. Educar, Curitiba, núm. 36, p. 181-213, Enero de 2010. 